\title{
The efficacy, safety, and cost-effectiveness of conventional synthetic disease-modifying anti- rheumatic drugs triple therapy in preventing relapse in rheumatoid arthritis patients: a randomized controlled trial (ESCoRT study)
}

Juan Zhao ( $\square$ juanzi810819@163.com )

Department of rheumatology and clinical immunology, Beijing, China

Wei Zhou

Peking University First Hospital

\section{Yangfeng Wu}

Peking University Health Science Center

Xiaoyan Yan

Peking University Health Science Center

Li Yang

Peking University Health Science Center

Zhuoli Zhang

Peking University First Hospital

\section{Research article}

Keywords: rheumatoid arthritis, conventional synthetic disease-modifying anti-rheumatic drugs, tumor necrosis factor inhibitors, relapse, cost-effectiveness

Posted Date: November 3rd, 2021

DOI: https://doi.org/10.21203/rs.3.rs-1022084/v1

License: (c) (i) This work is licensed under a Creative Commons Attribution 4.0 International License.

Read Full License 


\section{Abstract}

\section{Background}

Tumor necrosis factor inhibitors (TNFi) have been widely used in rheumatoid arthritis (RA) patients who failed to conventional synthetic disease-modifying anti-rheumatic drugs (csDMARDs). But how to prevent relapse after discontinuation of TNFi remains challengeable.

Methods

RA patients who failed to csDMARDs received an induction therapy of MTX+TNFi for maximally 12 weeks. Those achieving LDA in 12 weeks were randomly assigned at a 1:1:1 ratio into three groups: (A) adding hydroxychloroquine and sulfasalazine for the first 12 weeks and then discontinuing TNFi for the following 48 weeks; (B) maintaining TNFi+MTX for 60 weeks; and (C) maintaining TNFi+MTX for the first 12 weeks and then discontinuing TNFi for the following 48 weeks. The primary outcome was relapse.

Results

117 patients were enrolled for induction therapy and 67 patients who achieved LDA within 12 weeks were randomized, with 24,21 and 22 patients in each group. The relapse rates during 60 weeks were comparable between group A and B [10/22 (45.5\%) vs $7 / 20$ (35\%), $p=0.491]$, however, both significantly lower than that of group $C[17 / 20$ (85\%), $p=0.019, p=0.004$, respectively]. Taken $¥ 100000$ as the threshold of willingness to pay, compared to MTX monotherapy, both TNFi maintenance and triple csDMARDs therapies were cost-effective, but triple therapy was better.

Conclusion

For RA patients achieving LDA with TNFi and MTX, csDMARDs triple therapy was a cost-effective option in favor of reducing relapse.

Trial registration

Registration number: NCT02320630.

\section{Introduction}

Treat-to-target strategy with clinical remission or low disease activity (LDA) as goal, has been the core management of rheumatoid arthritis (RA) for a decade [1]. Biological agents, such as tumor necrosis factor inhibitors (TNFi), have been widely used and greatly improved goal achievement. But how to maintain the patients in remission/LDA remains an open question.

Undoubtedly, long-term use of biologics brings heavy economic burden. For the cost as well as safety reasons, discontinuation of biologics is common in RA patients who have achieved remission or LDA, but meanwhile increases the risk of relapse. European League Against Rheumatism (EULAR) recommends 
that tapering or discontinuing biologics can be considered for patients in persistent remission [2], but no detailed guidance to successful discontinuation was provided. Plenty of evidence showed that methotrexate (MTX) monotherapy could hardly maintain remission after TNFi discontinuation, with a relapse rate of $19 \%-75 \%$ [3-7]. Flare after TNFi discontinuation was associated with joint damage progression, especially when elevated disease activity persisted [8]. Based on some researches showing the comparable maintenance of remission in patients receiving half-dose and full-dose of TNFi, however both better than stopping TNFi in RA patients who achieved remission with TNFi [9], tapering via dose reduction or increasing intervals of injection is preferred to sharp discontinuation. Nevertheless, more cost-effective strategies are needed.

Conventional synthetic disease-modifying anti-rheumatic drugs (csDMARDs) are much cheaper [10], with less than $10 \%$ of annual cost of biologics in China. In RA patients who failed to MTX, adding hydroxychloroquine (HCQ) and sulfasalazine (SSZ) to MTX (called triple therapy thereafter) was shown the same efficacy and safety as adding a biological agent to MTX [11, 12]. Past evidence has shown the superior efficacy of csDMARDs combination to monotherapy [13]. The efficacy and safety of the triple therapy have also been proved in lots of global trials [14-17].

In SWEFOT trial, early RA patients with insufficient response to MTX randomly received infliximab plus MTX or triple therapy. At the end of 2 years, a small but statistically significant difference in radiographic outcomes favoring the infliximab group, while disease activity, quality of life, and work loss were improved similarly in both groups, and no statistically significant differences in utility or quality-adjusted life years (QALY) gain was detected [18-21]. But whether the triple therapy is as effective as biologics in preventing relapse in RA patients who have achieved remission or LDA remains unclear.

This 1:1:1 randomized enrollment parallel group superiority study aimed to investigate whether the triple therapy was better in reducing RA relapse than MTX monotherapy, and meanwhile more cost-effective than continuing TNFi plus MTX in patients who have achieved at least LDA with TNFi and MTX. We tried to find out a more reasonable biologic-free strategy to maintain remission/LDA than MTX monotherapy. In this study, a biosimilar of Etanercept, a recombinant human tumor necrosis factor a receptor II: IgG Fc fusion protein (YiSaiPu) was used.

\section{Methods/design Study design}

This was a prospective, two-stage, multiple-center study. The first stage was an induction phase with YiSaiPu plus MTX for no more than 12 weeks. The full trial protocol can be accessed in previous publication [22]. In brief, patients who achieved LDA [defined as 28-joint disease activity score based on C-reactive protein DAS28-CRP $\leq 3.2$ ] at this stage were enrolled into the second stage, which was a randomized, evaluators blinded controlled trial of 60 weeks. At the second stage, all eligible patients were randomized into one of the three arms at a ratio of 1:1:1. For patients in group $A, H C Q$ and SSZ were 
added for the first 12 weeks and then YiSaiPu was stopped, but all other medications were continued for the following 48 weeks (intervention group). Patients in group B maintained YiSaiPu and MTX for the entire 60 weeks (control group 1). Patients in group C maintained YiSaiPu and MTX for the first 12 weeks, and then stopped TNFi but continued MTX for the following 48 weeks (control group 2). All the patients were followed up to 60 weeks, or when RA relapsed. The study flow-chart is shown in Figure S1.

This trial was approved by the Peking University Ethics Committee.

All the participants gave written informed consent.

\section{Participants}

Patients were recruited from 7 rheumatology centers. The major inclusion criteria were as following: (1) fulfilled the 2010 EULAR/ACR classification criteria of RA; (2) between 18 and 70 years old; (3) disease durations more than 6 months; (4) DAS28-CRP >3.2 after treatment with methotrexate alone or in combination with other csDMARDs for more than 3 months. Exclusion criteria included patients who were unable or unwilling to give informed consent; with insufficient response to or contraindications to MTX, HCQ or SSZ (including possible pregnancy); had contraindications to tumor necrosis factor inhibitors treatment; with grade IV changes of hands on X-ray. The detailed inclusion and exclusion criteria are listed in Table 1. 
Table 1

The inclusion and exclusion criteria of the study.

\section{Inclusion criteria}

1. Fulfill the 2010 EULAR/ACR classification criteria of RA

2. Disease duration $>6$ months

3. Age $\geq 18$ and $\leq 70$ years

4. Use MTX alone or combination with other csDMARDs for more than 3 months

5. DAS28-CRP> 3.2

Exclusion Criteria

1.Received any of the below therapies

A. Large surgical operations within 8 weeks

B. Ever use of any cell elimination therapy

C. Intravenous injection of rituximab or IL-6 inhibitor within 6 months

D. Intra-articular injection of glucocorticoid within 4 weeks

E. Live vaccines or live attenuated vaccines within 4 weeks

2.Having diseases or organ/tissue damages as any of the below

A. Autoimmune diseases other than RA. Patients combining with Sjogren Syndrome were permitted

B. Severe or uncontrolled cardiac disease, nervous system disease, pulmonary disease, renal disease, liver disease, endocrine disease (including diabetes mellitus) and gastrointestinal disease

C. Current or relapsing bacterial/viral/fungal/ mycobacterium/other infections (include but not limited to tuberculosis or atypical mycobacterium disease, granuloma in chest $\mathrm{X}$ ray, type $\mathrm{B}$ or type $\mathrm{C}$ hepatitis, HIV, Zoster)

D. Malignant disease

E. Nerve damage or other painful disease which may affect pain evaluation

3. Laboratory abnormalities

A. Serum creatinine $>130 \mathrm{umol} / \mathrm{L}$

B. ALT or AST >2 upper normal limitation, or total bilirubin>upper normal limitation

C. Platelet $<100 \times 109 / L$, or WBC $<3 \times 109 / L$

4. Hands $X$ ray shows IV grade RA according to ACR imaging staging

Note: EULAR: European League Against Rheumatism; ACR: American College of Rheumatology; RA: Rheumatoid Arthritis; MTX: methotrexate; csDMARDs: conventional synthetic disease modifying antirheumatic drugs; DAS28-CRP: 28-joint disease activity score based on C-reactive protein; HIV: human immunodeficiency virus; ALT: Alanine aminotransferase; AST: aspartate transaminase; WBC: white blood cell. 


\section{Inclusion criteria}

5. Previous severe adverse reaction with any experimental drugs

6. Pregnant or plan to be pregnant in 2 years, or nursing mothers

Note: EULAR: European League Against Rheumatism; ACR: American College of Rheumatology; RA: Rheumatoid Arthritis; MTX: methotrexate; csDMARDs: conventional synthetic disease modifying antirheumatic drugs; DAS28-CRP: 28-joint disease activity score based on C-reactive protein; HIV: human immunodeficiency virus; ALT: Alanine aminotransferase; AST: aspartate transaminase; WBC: white blood cell.

\section{Randomization}

The randomization was performed by a central random system, electronic interactive network answering system (IWRS), provided by Peking University Clinical Research Centre. Randomization information produced by IWRS using static block random method was under the responsibility of designated staffs in each study center. The blocked randomization, stratified by study center and gender of patients, was performed centrally at the visit when a patient reached LDA (V0, week 0$)$.

\section{Concomitant medications}

Prednisolone $>10 \mathrm{mg} /$ day or equivalent, other csDMARDs (leflunomide, azathioprine, cyclosporine, cyclophosphamide, tripterygium) and other biological agents were not permitted.

Nonsteroidal anti-inflammatory drugs were permitted, but the drug name, dosage and treatment duration should be recorded. Anti-hypertension medications, antidiabetic agents, nitrates, low dose aspirin and $\beta$ blocker were permitted if necessary.

\section{Follow up schedules and data to be collected}

A total of 14 visits were scheduled. Data collected at each visit are summarized in supplementary Table S1.

Subjects who relapsed or encountered intolerant adverse events before the end of the trial could exit the trial and receive empirical treatment. All patients who exited early were continuously followed up for the safety and cost-effectiveness analysis.

\section{Outcomes}

The primary outcome was disease relapse, defined as DAS28-CRP $>3.2$ with an increase of at least 0.6 .

The secondary outcomes were as following: the incremental cost-effectiveness ratio (ICER, incremental cost per reducing 1 case of relapse) during 60 weeks after randomization; change of disease activity at week 60 from baseline, assessed by DAS28-CRP, DAS28 based on erythrocyte sedimentation rate (DAS28ESR), clinical disease activity index (CDAI) and simplified disease activity index (SDAI); duration of maintaining LDA or clinical remission after randomization; change of modified Sharp score at week 60 
from baseline; ultrasonic remission at week 60; mean health assessment questionnaire - disability index (HAQ-DI) and EuroQol-5 dimension (EQ-5D) at week 60; and adverse events.

\section{The ultrasound assessment}

Ultrasound scan was performed by two rheumatologists who were experienced in ultrasonography and blinded to the patients' clinical data. 22 joints (bilateral wrists, metacarpophalangeal joints, proximal interphalangeal joints) were scanned for each patient, including longitudinal, transverse and special sectional views. A LOGIQ E9 ultrasound machine (GE, Germany) with a corresponding linear probe ML 615 was applied, using both gray scale (GS) and Power doppler (PD) modes. Doppler setting: 7.5-10 MHz, low wall filtering, pulse repetition frequency $700-1000 \mathrm{~Hz}$. The maximum gain was considered proper when Doppler signal was not detected beneath the cortical bone. 5 RA patients were randomly selected to test the inter-observer reliability of ultrasound evaluation between the two operators. Weighted kappa analysis showed excellent inter-observer reliability of 0.893 (95\% Cl 0.844-0.942) for GS and 0.923 (95\% Cl 0.857-0.988) for PD.

The interpretation of lesions was based on the definitions from OMERACT (Outcome Measures in Rheumatoid Arthritis Clinical Trials) [23]. The GS and PD synovitis were assessed by semi-quantitative scoring systems (0-3) proposed by Szkudlarek et al [24]. GS synovitis was classified as: $0=a b s e n t ; 1=$ mild (slight hypoechoic or anechoic image in joint capsule); $2=$ moderate (presence of elevation of articular capsule); $3=$ marked (important distension of articular capsule). The PD synovitis was classified as follows: $0=$ absent; $1=$ mild (one PD signal); $2=$ moderate (two or more PD signal, $<50 \%$ of intraarticular flow); $3=$ marked ( $>50 \%$ of intraarticular flow). The total GS/PD score was the sum of GS/PD score for all 22 joints in each patient. The physical examination and ultrasound scan of joints were blindly performed on the same visiting day.

\section{Blinding}

An independent assessment committee blinded to grouping was established for disease activity and clinical outcomes assessment. The operators of ultrasound were also blinded. The members of assessment committee, the ultrasound operators and investigators worked independently. In the case of serious adverse event (SAE) during study, nonblinding was permitted, and the relevant Institutional Review Board (IRB) and principal study site (Peking University First Hospital) would be informed and decide to continue or terminate the trial.

\section{Sample Size Calculation}

Sample size was calculated by PASS 11.0. Our hypothesis was that the relapse rate in group A (triple therapy group) was lower than that in group C (MTX monotherapy group) in 60 weeks after randomization. Based on the previous study, the relapse rate of group C (discontinuation of TNFi) was $38 \%$ within one year, while it was presumed to be $16 \%$ after adding SSZ plus HCQ (group A). At a power of 0.8 and a significance level of 0.05 (two-sides), using a 1:1:1 treatment allocation of enrollment, the 
required sample size was 61 for each group to detect the difference of relapse rate between the two arms. Assuming a 10\% dropout rate, the target sample size for recruitment was 204 (68 for each group).

\section{Statistical analysis}

All statistical analyses were performed using SAS 9.2.

The compatibility between the study groups at baseline was checked. Student's $t$ test or Wilcoxon rank sum test was used for quantitative variables. Chi-square test or Fisher's exact test was used for categorical variables. The Cochran-Mantel-Haenszel test or the Wilcoxon rank sum test was used for ordinal variables.

In the analysis of comparing the relapse rate between group $A$ and $C$, the intention-to-treat principle was followed. The estimation of the treatment effect with its confidence interval $(\mathrm{Cl})$ was analyzed by MantelHaenszel method stratified by study centers in consideration of its potential influence. Kaplan-Meier curves were used to show the difference of relapse among groups. The changes in disease activity, Sharp score, PD/GS synovitis score on ultrasound and HAQ score were compared among the 3 groups using the covariance analysis model. Per protocol analysis was conducted as the sensitivity analyses.

Analysis on pharmaceutical economics was performed parallelly to the clinical analysis. Decision tree based on per-protocol set was built to perform base case analysis and sensitivity analysis (Figure S2). We also conducted a series of one-way deterministic sensitivity analysis. In the cost-effectiveness analysis, the rate of non-relapse was taken as effectiveness. The direct costs, total costs, and average cost/effectiveness ratio of each treatment strategy were calculated. The incremental cost-effectiveness ratios of group $A$ and group $B$ against group $C$ were calculated. Cost-utility analysis was performed by using EQ-5D as the index of utility. The costs and average cost/utility ratio of each treatment strategy were calculated. The incremental cost-utility ratios of group $A$ and group $B$ against group $C$ were also calculated. The treatment strategy was considered as having cost-utility if the incremental cost-utility ratio was below 3 times of per capita gross domestic product (GDP) of China in the past year $(¥ 100000)$.

The costs included medical expenses and productivity lost (direct cost and indirect cost). Bootstrap was used to calculate the $95 \% \mathrm{Cl}$ of incremental cost-effectiveness ratio and draw the cost-effectiveness acceptability curve. The factors which may affect the analysis results were evaluated by one-way and probability sensitivity analysis. All the analyses were performed by TreeAgePro11.0 software.

Safety analysis was performed based on the safety set. The incidence of adverse events, serious adverse events and adverse reactions related to the study medications were described. Crosstabs were constructed to map the changes of laboratory indexes.

\section{Results}

Demographics and baseline clinical features of enrolled patients 
Among the 123 RA patients screened, 117 entered to the induction stage with a median age of 58.4 years and $81.2 \%$ female. 67 patients achieved DAS28-CRP $<3.2$ within 12 weeks after initiating MTX and TNFi treatment and then were randomized. There were 24,21 and 22 patients in group $A, B$ and $C$ in the randomization stage, respectively (Figure 1). 50 patients failed in entering the randomization stage due to adverse events (4 patients), lost to follow up (1 patients), protocol violation (1 patients) and no achievement of DAS28-CRP<3.2 (44 patients). During 60-week follow-up in randomization stage, there were 5 patients dropped out (Figure 1). The baseline demographics and clinical features of 67 enrolled patients are demonstrated in Table 2. 
Table 2

Comparison of baseline characteristics and outcomes among patients of the three groups in the randomization stage.

\begin{tabular}{|c|c|c|c|c|}
\hline & $\begin{array}{l}\text { Group A } \\
(n=24)\end{array}$ & $\begin{array}{l}\text { Group B } \\
(n=21)\end{array}$ & $\begin{array}{l}\text { Group C } \\
(n=22)\end{array}$ & $\begin{array}{l}\mathrm{P} \\
\text { value }\end{array}$ \\
\hline Age [year, median (min-max)] & $59.7(22-72)$ & $59.9(31-70)$ & $53.04(29-72)$ & 0.327 \\
\hline Gender ( $F \%)$ & $18(75.0 \%)$ & $17(81.0 \%)$ & $13(59.1 \%)$ & 0.260 \\
\hline $\mathrm{BMI}(\operatorname{mean} \pm S D)$ & $23.3 \pm 3.1$ & $23.6 \pm 3.3$ & $24.1 \pm 4.5$ & 0.787 \\
\hline $\begin{array}{l}\text { Disease duration } \\
\text { [months, median (min-max)] }\end{array}$ & $37(6-253)$ & $64(12-300)$ & $81(7-336)$ & 0.080 \\
\hline TJC [median (min-max)] & $2(0-5)$ & $1.5(0-6)$ & $1(0-5)$ & 0.434 \\
\hline SJC [median (min-max)] & $1(0-4)$ & $0.5(0-2)$ & $0(0-3)$ & 0.194 \\
\hline PGA [median (min-max)] & $20(10-45)$ & $30(5-70)$ & $20(0-50)$ & 0.099 \\
\hline EGA [median (min-max)] & $20(10-45)$ & $30(10-70)$ & $20(0-50)$ & 0.105 \\
\hline ESR [median (min-max)] & $18(2-100)$ & $15(4-46)$ & $19(2-45)$ & 0.889 \\
\hline CRP [median (min-max)] & $\begin{array}{l}3.01(1.22- \\
30.7)\end{array}$ & $\begin{array}{l}3.3(1.59- \\
34.28)\end{array}$ & $\begin{array}{l}4.18(1.14- \\
60.1)\end{array}$ & 0.814 \\
\hline RF [IU/ml, median (min-max)] & $161(0-1930)$ & $31.2(0-1010)$ & $50.8(0-3414)$ & 0.191 \\
\hline Anti-CCP & $20(90.9 \%)$ & $17(85 \%)$ & $18(90 \%)$ & 0.819 \\
\hline $\begin{array}{l}\text { DAS28-CRP } \\
\text { [median (min-max)] }\end{array}$ & $\begin{array}{l}2.88(1.71- \\
3.19)\end{array}$ & $\begin{array}{l}2.97(1.81- \\
3.19)\end{array}$ & $\begin{array}{l}2.74(1.34- \\
3.19)\end{array}$ & 0.728 \\
\hline DAS28-ESR (mean士SD) & $3.20 \pm 0.54$ & $3.06 \pm 0.63$ & $2.79 \pm 0.93$ & 0.247 \\
\hline SDAI [median (min-max)] & $\begin{array}{l}8.71(2.45- \\
12.55)\end{array}$ & $\begin{array}{l}9.40(3.23- \\
16.16)\end{array}$ & $\begin{array}{l}7.51(0.18- \\
4.14)\end{array}$ & 0.089 \\
\hline CDAI [median (min-max)] & $8.5(2-12)$ & $8.75(3-16)$ & $6(0-14)$ & 0.056 \\
\hline HAQ (mean $\pm S D)$ & $3.5(0-55)$ & $5.5(0-21)$ & $1(0-16)$ & 0.081 \\
\hline EQ-5D & $\begin{array}{l}0.869(0.505- \\
0.961)\end{array}$ & $\begin{array}{l}0.826(0.505- \\
0.961)\end{array}$ & $\begin{array}{l}0.872(0.591- \\
0.961)\end{array}$ & 0.321 \\
\hline
\end{tabular}

Note: BMI: body mass index; TJC: tender joint count; SJC: swollen joint count; PGA: patient global assessment; EGA: evaluator global assessment; ESR: erythrocyte sedimentation rate; CRP: C-reactive protein; RF: rheumatoid factor; anti-CCP: anti-cyclic citrullinated protein; DAS: disease activity score; SDAl: simplified disease; activity index; CDAl: clinical disease activity index; HAQ-DI: Health Assessment Questionnaire-Disability Index; EQ-5D: Euro Qol five dimension questionnaire; PD: power Doppler; GS: gray scale; LDA: low disease activity; BE: bone erosion; JSN: joint space narrow; mTSS: mean total sharp score. 


\begin{tabular}{|c|c|c|c|c|}
\hline & $\begin{array}{l}\text { Group A } \\
(n=24)\end{array}$ & $\begin{array}{l}\text { Group B } \\
(n=21)\end{array}$ & $\begin{array}{l}\text { Group C } \\
(n=22)\end{array}$ & $\begin{array}{l}\mathrm{P} \\
\text { value }\end{array}$ \\
\hline PD [median (min-max)] & $0(0-4)$ & $1.5(0-27)$ & $0.5(0-5)$ & 0.030 \\
\hline GS [median (min-max)] & $3.5(0-15)$ & $4(0-40)$ & $2.5(0-23)$ & 0.263 \\
\hline Relapse & $9(40.9 \%)$ & $7(35 \%)$ & $17(85 \%)$ & 0.001 \\
\hline $\begin{array}{l}\text { Duration of LDA/remission before } \\
\text { relapse (weeks) }\end{array}$ & $44.2 \pm 20.5$ & $40.5 \pm 23.9$ & $25.1 \pm 16.3$ & 0.010 \\
\hline \multicolumn{5}{|l|}{ Sharp Score Progression } \\
\hline BE & $0(0-2)$ & $0(0-3)$ & $0.5(0-6)$ & 0.179 \\
\hline JSN & $1(0-3)$ & $1(-1-7)$ & $1(-1-8)$ & 0.751 \\
\hline mTSS & $1(0-4)$ & $1(-1-9)$ & $1.5(-1-14)$ & 0.938 \\
\hline \multicolumn{5}{|c|}{$\begin{array}{l}\text { Note: BMI: body mass index; TJC: tender joint count; SJC: swollen joint count; PGA: patient global } \\
\text { assessment; EGA: evaluator global assessment; ESR: erythrocyte sedimentation rate; CRP: C-reactive } \\
\text { protein; RF: rheumatoid factor; anti-CCP: anti-cyclic citrullinated protein; DAS: disease activity score; } \\
\text { SDAl: simplified disease; activity index; CDAl: clinical disease activity index; HAQ-DI: Health } \\
\text { Assessment Questionnaire-Disability Index; EQ-5D: Euro Qol five dimension questionnaire; PD: power } \\
\text { Doppler; GS: gray scale; LDA: Iow disease activity; BE: bone erosion; JSN: joint space narrow; mTSS: } \\
\text { mean total sharp score. }\end{array}$} \\
\hline
\end{tabular}

Predictive factors for achievement of LDA with TNFi and MTX treatment within 12 weeks

Sixty-seven out of 117 (57.3\%) patients achieved LDA after initiating TNFi plus MTX treatment within 12 weeks. Comparing with 44 patients who did not achieve LDA, the patients who achieved LDA had lower proportion of female, shorter disease duration, fewer baseline TJC, lower baseline disease activity and lower baseline HAQ-DI (Table 3). Multiple logistic regression analysis showed that male gender and few TJC were predictive factors for the achievement of LDA with TNFi and MTX treatment within 12 weeks (Table S2). 
Table 3

Comparison of baseline characteristics between patients achieved and not achieved DAS28-CRP $<3.2$ in the induction stage.

\begin{tabular}{|c|c|c|c|c|}
\hline & $\begin{array}{l}\text { Total patients enrolled } \\
\text { in the induction stage } \\
(n=111)\end{array}$ & $\begin{array}{l}\text { Patients achieved } \\
\text { DAS28-CRP<3.2 } \\
(n=67)\end{array}$ & $\begin{array}{l}\text { Patients not achieved } \\
\text { DAS28-CRP }<3.2 \\
(n=44)\end{array}$ & $\begin{array}{l}P \\
\text { value }\end{array}$ \\
\hline $\begin{array}{l}\text { Age [year, } \\
\text { median (min- } \\
\text { max)] }\end{array}$ & $58.4(22-72)$ & $59.0(22-72)$ & $57.0(24-72)$ & 0.356 \\
\hline Gender (F\%) & 91 (81.2\%) & 48 (71.6\%) & $43(97.7 \%)$ & 0.001 \\
\hline $\begin{array}{l}\text { BMI } \\
(\text { mean } \pm S D)\end{array}$ & $23.8 \pm 3.8$ & $23.6 \pm 3.6$ & $23.9 \pm 4.0$ & 0.578 \\
\hline $\begin{array}{l}\text { Disease } \\
\text { duration }\end{array}$ & $76(6-408)$ & $62(6-336)$ & $114(6-408)$ & 0.053 \\
\hline $\begin{array}{l}\text { [months, } \\
\text { median (min- } \\
\text { max)] }\end{array}$ & & & & \\
\hline $\begin{array}{l}\text { TJC [median } \\
(\text { min-max })]\end{array}$ & $10(1-28)$ & $8(2-18)$ & $12.5(1-28)$ & 0.002 \\
\hline $\begin{array}{l}\text { SJC [median } \\
\text { (min-max)] }\end{array}$ & $4(0-21)$ & $4(0-21)$ & $5(0-18)$ & 0.095 \\
\hline $\begin{array}{l}\text { PGA [median } \\
\text { (min-max)] }\end{array}$ & $60(20-90)$ & $60(20-90)$ & $70(20-90)$ & 0.354 \\
\hline $\begin{array}{l}\text { EGA [median } \\
(\text { min-max })]\end{array}$ & $60(10-90)$ & $50(10-90)$ & $60(20-90)$ & 0.058 \\
\hline $\begin{array}{l}\text { ESR [median } \\
\text { (min-max)] }\end{array}$ & $33(2-170)$ & $4(2-105)$ & $33(6-170)$ & 0.345 \\
\hline $\begin{array}{l}\text { CRP [median } \\
\text { (min-max)] }\end{array}$ & $15.0(1.27-143)$ & $14.7(1.27-104)$ & $14.9(1.42-138)$ & 0.693 \\
\hline RF positive (\%) & $81(73.0 \%)$ & 48 (71.6\%) & 33 (75\%) & 0.697 \\
\hline $\begin{array}{l}\text { Anti-CCP } \\
\text { positive (\%) }\end{array}$ & 96 (86.5\%) & 60 (89.6\%) & $36(81.8 \%)$ & 0.371 \\
\hline $\begin{array}{l}\text { DAS28-CRP } \\
\text { [median (min- } \\
\text { max)] }\end{array}$ & $5.11(3.41-7.89)$ & $4.74(3.50-7.89)$ & $5.47(3.41-7.47)$ & 0.004 \\
\hline $\begin{array}{l}\text { DAS28-ESR } \\
(\text { mean } \pm S D)\end{array}$ & $5.68 \pm 1.15$ & $5.41 \pm 1.12$ & $6.05 \pm 1.10$ & 0.004 \\
\hline \multicolumn{5}{|c|}{$\begin{array}{l}\text { Note: BMI: body mass index; TJC: tender joint count; SJC: swollen joint count; ESR: erythrocyte } \\
\text { sedimentation rate; CRP: C-reactive protein; RF: rheumatoid factor; anti-CCP: anti-cyclic citrullinated } \\
\text { protein; DAS: disease activity score; SDAl: simplified disease; activity index; CDAl: clinical disease } \\
\text { activity index; HAQ-DI: Health Assessment Questionnaire-Disability Index; }\end{array}$} \\
\hline
\end{tabular}




\begin{tabular}{|c|c|c|c|c|}
\hline & $\begin{array}{l}\text { Total patients enrolled } \\
\text { in the induction stage } \\
(n=111)\end{array}$ & $\begin{array}{l}\text { Patients achieved } \\
\text { DAS28-CRP<3.2 } \\
(n=67)\end{array}$ & $\begin{array}{l}\text { Patients not achieved } \\
\text { DAS28-CRP<3.2 } \\
(\mathrm{n}=44)\end{array}$ & $\begin{array}{l}\mathrm{P} \\
\text { value }\end{array}$ \\
\hline $\begin{array}{l}\text { SDAl [median } \\
\text { (min-max)] }\end{array}$ & $27.42(10.76-69.39)$ & $24.46(11.48-69.39)$ & $35.85(10.76-62.6)$ & 0.003 \\
\hline $\begin{array}{l}\text { CDAI [median } \\
(\text { min-max)] }\end{array}$ & $26(9-62)$ & $24(10-62)$ & $33(9-57)$ & 0.004 \\
\hline $\begin{array}{l}\text { HAQ-DI } \\
(\text { mean } \pm S D)\end{array}$ & $1.03 \pm 0.60$ & $0.90 \pm 0.57$ & $1.25 \pm 0.60$ & 0.003 \\
\hline $\begin{array}{l}\text { PD [median } \\
\text { (min-max)] }\end{array}$ & $2(0-38)$ & $2(0-38)$ & $2(0-20)$ & 0.710 \\
\hline $\begin{array}{l}\text { GS [median } \\
(\text { min-max)] }\end{array}$ & $6(0-56)$ & $5(0-56)$ & $6(0-37)$ & 0.312 \\
\hline \multicolumn{5}{|c|}{$\begin{array}{l}\text { Note: BMI: body mass index; TJC: tender joint count; SJC: swollen joint count; ESR: erythrocyte } \\
\text { sedimentation rate; CRP: C-reactive protein; RF: rheumatoid factor; anti-CCP: anti-cyclic citrullinated } \\
\text { protein; DAS: disease activity score; SDAl: simplified disease; activity index; CDAl: clinical disease } \\
\text { activity index; HAQ-DI: Health Assessment Questionnaire-Disability Index; }\end{array}$} \\
\hline
\end{tabular}

The clinical features of patients at randomization and their clinical outcomes in three groups

Eventually, 67 patients entered the randomization stage, with a median age of 59 years and $71.6 \%$ female. At randomization, their clinical features were similar among three groups, except for a bit higher PD score in group B. During follow-up of 60 weeks, relapse was observed in 10/22 (45.5\%), 7/20 (35\%) and $17 / 20$ (85\%) patients in three groups, respectively (Figure 2). The relapse rates in group $A$ and group $B$ were comparable $(p=0.491)$, however both higher than that in group $C(p=0.019, p=0.004$, respectively). Interestingly, the LDA maintenance duration before relapse was significantly shorter in group $B$ than that in group $A$ and group $C(9.5 \pm 5.3$ weeks vs. $21.2 \pm 10.0$ weeks, $p=0.014 ; 9.5 \pm 5.3$ weeks vs. $19.0 \pm 7.0$ weeks, $p=0.004)$, although no difference was found between group $A$ and group $C(p=0.623)$.

For those patients who did not relapse, the disease activity assessed by DAS28-CRP, DAS28-ESR, CDAI and SDAl, as well as HAQ-DI and EQ-5D was all comparable among three groups at week 60 (Table S3).

\section{The radiological outcomes of the patients in three groups}

The modified Sharp score was evaluated by X-ray of bilateral wrists and hands. The bone erosion score, joint space narrowing score and modified total sharp score were comparable among three groups at baseline. The changes of all these radiological scores at the end of week 60 from baseline were similar among three groups.

48 out of 67 patients received ultrasound examination at randomization and 20 non-flared patients received repeated ultrasound scan at week 60 . Overall, the proportion of patients with PD synovitis was significantly decreased $(p=0.010)$, but not with GS synovitis $(p=0.294)$. Further analysis in separate 
groups showed that both total PD score and GS score were significantly decreased in patients of group B and the proportion of patients with PD synovitis was also significantly decreased in group B only $(p<0.001)$ (Table S4). In patients of group A, only GS score was decreased, whereas, neither PD nor GS synovitis was improved in patients of group C (Table S5).

\section{The cost-effectiveness and cost-utility analysis among three groups}

Direct cost-effectiveness analysis and total cost-effectiveness analysis are shown in Figure S3. The costeffectiveness and cost-utility analysis for the three therapeutic strategies are presented in Table S6 and Table S7. The triple therapy had the lowest average direct cost-effectiveness ratio, total cost-effectiveness ratio, direct cost-utility ratio and total cost-utility ratio. Compared to MTX monotherapy, both TNFi maintenance and triple therapy had cost-effectiveness, but only triple therapy had cost-utility, when $¥ 100000$ was taken as the threshold of willingness to pay (WTP). Compared to triple therapy, TNFi maintenance therapy had neither cost-effectiveness nor cost-utility.

The tornado analysis indicated that the most influential parameter was the cost of TNFi. The ICER was decreased from $¥ 3.0$ million per QALY to $¥ 0.278$ million per QALY if the cost of TNFi was reduced from $¥ 1300$ to $¥ 100$ per week (Figure S4).

TNFi maintenance therapy would gain better net monetary benefit of utility when the TNFi cost per week was reduced to $¥ 130.54$ or less (Figure S5), and better net monetary benefit of effectiveness (evaluated by relapse-free rate) when the weekly cost was $¥ 399.16$ or less (Figure S6).

\section{The adverse effects}

All the 117 patients were included for the safety analysis. There were $62(55.6 \%)$ patients with various adverse events, including elevated aminotransferase $(27,23.1 \%)$, upper respiratory tract infection (18, $15.4 \%)$, rash $(14,12.0 \%)$, gastro-intestinal symptoms $(10,8.5 \%)$, leukocytopenia $(8,6.8 \%)$, pruritus $(6$, $5.1 \%)$, urinary tract infection $(2,1.7 \%)$, pneumonia $(2,1.7 \%)$, and hyperlipidemia, periodontitis, edema of lower extremities, herpes zoster, anemia, new onset hypertension ( 1 each, $0.9 \%$ ), respectively. In the induction stage, 4 patients withdrew from the study due to adverse events (1 each with pneumonia, severe skin allergy, herpes zoster, and liver damage with leukocytopenia). No severe adverse events were observed.

Among the 67 patients enrolled into the randomization stage, adverse reactions were observed in 37 (55.2\%) patients, which was similar to that in total safety set. Most adverse effects were comparable among the three groups, except for more frequent gastro-intestinal symptoms in patients of group $A$ than group $B[p=0.011]$ and group $C[p=0.001]$ (Table 4). No dropout due to adverse events occurred in the randomization stage. 
Table 4

Adverse effect among the three groups.

\begin{tabular}{|lllll|}
\hline & $\begin{array}{l}\text { Group A } \\
(\mathbf{n = 2 4 )}\end{array}$ & $\begin{array}{l}\text { Group B } \\
\mathbf{( n = 2 1 )}\end{array}$ & $\begin{array}{l}\text { Group C } \\
\mathbf{( n = 2 2 )}\end{array}$ & P value \\
\hline Total adverse events & $12(50 \%)$ & $12(57.2 \%)$ & $13(59.1 \%)$ & 0.807 \\
\hline Liver damage & $5(20.8 \%)$ & $7(33.3 \%)$ & $6(27.3 \%)$ & 0.640 \\
\hline Upper respiratory tract infection & $3(12.5 \%)$ & $7(33.3 \%)$ & $6(27.3 \%)$ & 0.217 \\
\hline Rash & $1(4.2 \%)$ & $1(4.8 \%)$ & $2(9.1 \%)$ & 0.761 \\
\hline Gastrointestinal involvement & $8(33.3 \%)$ & $1(4.8 \%)$ & 0 & 0.001 \\
\hline Pruritus & $1(4.2 \%)$ & $1(4.8 \%)$ & $1(4.5 \%)$ & 0.995 \\
\hline Leukocytopenia & $3(12.5 \%)$ & $2(9.5 \%)$ & $1(4.5 \%)$ & 0.615 \\
\hline Urinary tract infection & 0 & $1(4.8 \%)$ & $1(4.5 \%)$ & 0.405 \\
\hline Anemia & $1(4.2 \%)$ & 0 & 0 & 0.353 \\
\hline Hyperlipide & 0 & 0 & $1(4.5 \%)$ & 0.323 \\
\hline Paradentitis & 0 & 0 & $1(4.5 \%)$ & 0.323 \\
\hline
\end{tabular}

\section{Discussion}

In the current study, we evaluated the cost-effectiveness, safety and efficacy in preventing relapse of triple csDMARDs therapy (MTX+HCQ+SSZ) in comparison with MTX monotherapy and continuation of TNFi plus MTX among RA patients achieving LDA or remission. We found triple therapy was superior to MTX monotherapy in preventing relapse and meanwhile more cost-effective than TNFi maintenance therapy.

With wide application of biological agents, more RA patients have been able to achieve remission or LDA. But the great "unmet need" currently lies in the appropriate strategy to maintain remission or LDA after reduction or discontinuation of biologics. Previous studies showed that $19 \%-75 \%$ of patients relapsed in 12 months after discontinuation of TNFi [3-5]. In our trial the relapse rate was as high as $85 \%$, although TNFi and MTX were continued for additional 12 weeks before cessation. MTX monotherapy for maintenance after discontinuing TNFi has been proved inappropriate. Some studies showed that discontinuation of biologics was associated with an increased risk of losing remission whereas tapering was not $[25,26]$. EULAR also recommends tapering biologics can be considered for RA patient in sustained remission [8], nevertheless, biological therapy with taping dose remains expensive indeed and whether tapering can contribute to final withdrawing is unknown.

The efficacy and safety of MTX, HCQ and SSZ triple therapy have been proved for decades [14-17]. Several randomized controlled trials also demonstrated its similar efficacy to TNFi in combination with 
MTX in RA [14, 27]. For instance, the TEAR study showed similar mean DAS28 during weeks 48-102 in patients receiving MTX plus etanercept and triple therapy [12]. Given the similar outcomes however huge difference in cost, triple therapy was found to be more durable than MTX-etanercept therapy in patients with inadequate response to MTX [28]. Moreover, triple therapy showed almost similar safety profiles to TNFi plus MTX therapy, except for slightly higher non-serious gastrointestinal symptoms and lower infectious events reported in some studies $[29,30]$.

Whether the triple therapy is as effective as biologics in preventing RA relapse in patients who have achieved remission or LDA remains unclear. A previous study showed that combination therapy of MTX and cyclosporin did not prevent RA relapse in 58\% patients with LDA after discontinuation of TNFi [4]. We noticed that TNFi was stopped exactly at the initiation of combination therapy, which we think may explain the high frequency of flare in the study, as cyclosporin usually takes several weeks to take effect. Therefore, in the current study, adding HCQ and SSZ was required for 12 weeks before TNFi cessation. Importantly, we found relapse rates were pretty similar in patients receiving triple therapy and TNFi maintenance therapy, indicating triple therapy can be an alternative to biologics on the premise of 12week's overlap therapy. To be noted, this conclusion derived from RA patients who have achieved LDA with MTX and TNFi therapy for no more than 12 weeks may not be appropriate for other clinical situations.

Plenty of studies have demonstrated better cost-effectiveness of triple therapy than biologics. RACAT study showed that etanercept-MTX was superior in efficacy however with a higher ICER compared with triple therapy for active RA patients with inadequate response to MTX [31]. A Swedish study calculated that infliximab would cost $€ 20916$ more than triple therapy over a period of 21 months and provided only 0.01 additional QALY, resulting in an ICER of $€ 2404197$ per QALY [27]. A UK study showed adalimumab, etanercept, or infliximab cost $\$ 8586$ more than csDMARDs combinations over a period of 12 months, however no difference in EQ-5D [32]. Choi et al. reported that comparing with MTX monotherapy, entanercept+MTX and MTX+CsA regimens, triple therapy was the most cost-effective option for MTXresistant RA patients [33]. A Chinese study also reported similar results [34].

It is noteworthy that we do not mean biologics should be abandoned from csDMARDs resistant RA patients who have achieved remission by TNFi plus MTX, rather triple therapy should be recommended in preference to biologics for the sake of cost savings. The TNFi we used in this trial was a biosimilar to etanercept, which was cheaper. The cost of biosimilars has been continuously decreasing in China in recent years. Moreover, the reimbursement policy of biologics will make the cost-effective margin between triple therapy and TNFi smaller.

There are a couple of novelties of our trial. We designed an overlap of triple csDMARDs with TNFi for 12 weeks as bridging therapy to prevent relapse. Besides, the cost-effective and cost-utility analysis were conducted in RA patients who have achieved therapy target. Most previous studies compared the pharmacoeconomics of triple therapy and biologics in improving disease activity of RA patients, but few studies focused on the efficacy of maintenance of remission. 
We are aware of the limitations in this study. First, both patients and investigators were not blinded based on the open labelled design. But clinical evaluators and ultrasound operators were blinded of grouping and treatment, which maximally guaranteed the objectivity of the study. Second, it was a pilot study with limited sample size. Although the targeted number of enrolled patients was not reached, the primary endpoint has been achieved. This was mainly attributable to the underestimation of flare risk of each group. There were no precise data available for reference when we designed the study. Considering that larger sample size will not make difference in the conclusion, we terminated the trial early. Furthermore, the significantly higher relapse rate in MTX monotherapy group made it inappropriate to enlarge the sample size for ethical consideration. Third, the potential long-term cost-effective analysis was not able to be performed because of the inherent shortcomings in observation period of the trial.

\section{Conclusions}

For RA patients who achieved clinical target with TNFi and MTX, the MTX, HCQ and SSZ triple therapy is as effective as TNFi maintenance therapy in reducing relapse, however more cost-effective. Triple therapy can be used as an alternative to TNFi for maintenance.

\section{Declarations}

- Ethics approval and consent to participate

This trial was approved by the Peking University Ethics Committee (approval number: IRB0000105213058 ). The ICF obtained from study participants was written formally.

- Consent for publication

The submission was agreed by all the authors

- Availability of supporting data

The data will be sent to the editorial office if necessary.

- Competing interests

None declared.

- Funding

The study was supported by the Peking University Clinical Research Program (PUCRP201305).

- Authors' contributions

ZZ conceived of the study, participated in its design and, managed and coordinated the study as the primary investigator. She also critically revised the manuscript and made the decision to submit the 
manuscript for publication. WZ contributed to the initial design of the trial. JZ was responsible for the patient enrollment, patient assignment to interventions and follow-up as the sub program investigator. She had full access to all of the data collection, analysis, interpretation, and drafted the manuscript. YW inspected and supervised the study. LY designed the pharmacoeconomic questionnaire and analyzed the pharmacoeconomic data. XY was responsible for the statistical problem. All authors read and approved the final manuscript.

\section{- Acknowledgements}

The Data Management Department of Peking University Clinical Research Institute (PUCRI-DM) was appreciated. We acknowledged Shenyang Sunshine Pharmaceutical Co., Ltd. for supporting the research drug of YiSaiPu. We acknowledged Yuhang Liu, Xiaojun Meng for the physical examination and disease activity evaluation of subjects, Li Wang for the administration of research drug and Qin Liu for the contribution of database building.

The authors thank all the participating patients in this study.

\section{References}

1. Smolen JS, Aletaha D, Bijlsma JW, Breedveld FC, Boumpas D, Burmester G, et al. Treating rheumatoid arthritis to target: recommendations of an international task force. Ann Rheum Dis 2010 Apr;69(4):631-7

2. Smolen JS, Landewé RBM, Bijlsma JWJ, Burmester GR, Dougados M, Kerschbaumer A, et al. EULAR Recommendations for the Management of Rheumatoid Arthritis With Synthetic and Biological Disease-Modifying Antirheumatic Drugs: 2019 Update. Ann Rheum Dis. 2020 Jun;79(6):685-99.

3. Smolen JS, Emery P, Fleischmann R, van Vollenhoven RF, Pavelka K, Durez P, et al. Adjustment of therapy in rheumatoid arthritis on the basis of achievement of stable low disease activity with adalimumab plus methotrexate or methotrexate alone: the randomised controlled OPTIMA trial. Lancet. 2014;383(9914): 321-32

4. Migliore A, Bizzi E, Massafra U, Vacca F, Martin Martin LS, Ferlito C, et al. A new chance to maintain remission induced by anti-TNF agents in rheumatoid arthritis patients: CYnAR study II of a 12-month follow-up. Int J Immunopathol Pharmacol. 2011, 24(1): 167-74.

5. Brocq O, Millasseau E, Albert C, Grisot C, Flory P, Roux CH, et al. Effect of discontinuing TNFalpha antagonist therapy in patients with remission of rheumatoid arthritis. Joint Bone Spine, 2009, 76(4): 350-5.

6. van den Broek M1, Klarenbeek NB, Dirven L, van Schaardenburg D, Hulsmans HM, Kerstens PJ, et al. Discontinuation of infliximab and potential predictors of persistent low disease activity in patients with early rheumatoid arthritis and disease activity score-steered therapy: subanalysis of the BeSt study. Ann Rheum Dis, 2011, 70 (8); 1389-94. 
7. Navarro-Millán I, Sattui SE, Curtis JR. Systematic review of tumor necrosis factor inhibitor discontinuation studies in rheumatoid arthritis. Clin Ther. 2013 Nov;35(11): 1850-61

8. Smolen JS, Pedersen $\mathrm{R}$, Jones $\mathrm{H}$, et al. Impact of flare on radiographic progression after etanercept continuation, tapering or withdrawal in patients with rheumatoid arthritis. Rheumatology 2020;59:153-64.

9. Smolen JS, Nash P, Durez P, Hall S, llivanova E, Irazoque-Palazuelos F, et al. Maintenance, reduction, or withdrawal of etanercept after treatment with etanercept and methotrexate in patients with moderate rheumatoid arthritis (PRESERVE): a randomized controlled trial. Lancet. 2013;381(9870):918-29.

10. Hetland ML, Christensen IJ, Tarp U, Dreyer L, Hansen A, Hansen IT, et al. Direct comparison of Treatment responses, remission rates, and drug adherence in patients with rheumatoid arthritis treated with adalimumab, etanercept, or infliximab. Arthritis Rheum, 2010, 62 (1): 22-32.

11. van Vollenhoven RF, Ernestam S, Geborek P, Petersson IF, Co " sterL, Waltbrand E, et al. Addition of infliximab compared with addition of sulfasalazine and hydroxychloroquine to methotrexate in patients with early rheumatoid arthritis (Swefot trial): 1-year results of a randomised trial. Lancet. 2009;374:459-66.

12. Moreland LW, O'Dell JR, Paulus HE, Curtis JR, Bathon JM, St. Clair EW, et al. A Randomized Comparative Effectiveness Study of Oral Triple Therapy Versus Etanercept Plus Methotrexate in Early Aggressive Rheumatoid Arthritis: The Treatment of Early Aggressive Rheumatoid Arthritis Trial. Arthritis Rheum. 2012 Sep;64(9):2824-35.

13. Choy EHS, Smith C, Dore CJ, Scott DL. A meta-analysis of the efficacy and toxicity of combining disease-modifying anti-rheumatic drugs in rheumatoid arthritis based on patient withdrawal. Rheumatology, 2005, 44 (11): 1414-21.

14. O'Dell JR, Haire CE, Erikson N, Drymalski W, Palmer W, Eckhoff PJ, et al. Treatment of Rheumatoid Arthritis with Methotrexate Alone, Sulfasalazine and Hydroxychloroquine, or a Combination of All Three Medications. N Engl J Med. 1996;334(20):1287-91.

15. Rantalaiho V, Sandström T, Koski J, Hannonen P, Möttönen T, Oili KS, et al. Early Targeted Combination Treatment with csDMARDs Sustains Excellent Long-term Outcomes in Rheumatoid Arthritis. Arthritis Care Res (Hoboken). 2018 Oct 8.

16. Bae SC, Lee YH. Comparative efficacy and safety of TNF-inhibitor plus methotrexate versus oral triple therapy in patients with active rheumatoid arthritis inadequately responding to methotrexate: A meta-analysis of randomized controlled trials. Int J Clin Pharmacol Ther. 2018 Jun;56(6):263-269.

17. Soliman MM, Ashcroft DM, Watson KD, Lunt M, Symmons DP, Hyrich KL, et al. Impact of concomitant use of DMARDs on the persistence with anti-TNF therapies in patients with rheumatoid arthritis: results from the British Society for Rheumatology Biologics Register. Ann Rheum Dis. 2011; 70(4): 583-9. 
18. Eriksson JK, Karlsson JA, Bratt J, Petersson IF, van Vollenhoven RF, Ernestam S, et al. Costeffectiveness of infliximab versus conventional combination treatment in methotrexate-refractory early rheumatoid arthritis: 2-year results of the register-enriched randomised controlled SWEFOT trial. Ann Rheum Dis. 2015;74:1094-101.

19. Eriksson JK, Neovius M, Bratt J, Petersson IF, van Vollenhoven RF, Geborek P, et al. Biological vs. conventional combination treatment and work loss in early rheumatoid arthritis: a randomized trial. JAMA Intern Med 2013;173:1407-14.

20. Karlsson JA, Neovius M, Nilsson JA, Petersson IF, Bratt J, van Vollenhoven RF, et al. Addition of infliximab compared with addition of sulfasalazine and hydroxychloroquine to methotrexate in early rheumatoid arthritis: 2-year quality of life results of the randomised, controlled, SWEFOT trial. Ann Rheum Dis 2013;72:1927-33.

21. Van Vollenhoven RF, Geborek P, Forslind K, Albertsson K, Ernestam S, Petersson IF, et al. Conventional combination treatment versus biological treatment in methotrexate-refractory early rheumatoid arthritis: 2 year followup of the randomised, nonblinded, parallel-group Swefot trial. Lancet 2012;379:1712-20.

22. Zhao J, Zhou W, Wu Y, Ji P, Yang L, Yan X, Zhang Z. The efficacy, safety and cost-effectiveness of hydroxychloroquine, sulfasalazine, methotrexate triple therapy in preventing relapse among patients with rheumatoid arthritis achieving clinical remission or low disease activity: the study protocol of a randomized controlled clinical Trial (ESCoRT study). BMC Med Inform Decis Mak. 2021;21:83.

23. Wakefield RJ, Balint PV, Szkudlarek M, Filippucci E, Backhaus M, D'Agostino MA et al Musculoskeletal ultrasound including definitions for ultrasonographic pathology. J Rheumatol 2005 Dec;32(12):2485-7

24. Szkudlarek M, Court-Payen M, Jacobsen S, Klarlund M, Thomsen HS, Ostergaard M. Interobserver agreement in ultrasonography of the finger and toe joints in rheumatoid arthritis. Arthritis Rheum 2003 Apr;48(4):955-62

25. Henaux S, Ruyssen-Witrand A, Cantagrel A, Barnetche T, Fautrel B, Filippi N, et al. Risk of losing remission, low disease activity or radiographic progression in case of bDMARD discontinuation or tapering in rheumatoid arthritis: systematic analysis of the literature and meta-analysis. Ann Rheum Dis 2018;777:515-22.

26. Verhoef LM, Tweehuysen L, Hulscher ME, Fautrel B, den Broeder AA. bDMARD dose reduction in rheumatoid arthritis: a narrative review with systematic literature search. Rheumatol Ther 2017;4:124.

27. O'Dell JR, Mikuls TR, Taylor TH, Ahluwalia V, Brophy M, Warren SR, et al. Therapies for active rheumatoid arthritis after methotrexate failure. N Engl J Med. 2013; 369(4):307-18.

28. Peper SM, Lew R, Mikuls T, Brophy M, Rybin D, Wu H, et al. Arthritis Care Res (Hoboken). Rheumatoid Arthritis Treatment After Methotrexate: The Durability of Triple Therapy Versus Etanercept. 2017 Oct;69(10):1467-1472. 
29. Kang EH, Jin Y, Tong AY, Desai RJ, Kim SC. Risk of serious infection among initiators of TNF inhibitors plus methotrexate versus triple therapy for rheumatoid arthritis: a cohort study. Arthritis Care Res (Hoboken). 2020 Oct;72(10):1383-1391.

30. Quach LT, Chang BH, Brophy MT, Soe Thwin S, Hannagan K, O'Dell JR. Rheumatoid arthritis triple therapy compared with etanercept: difference in infectious and gastrointestinal adverse events. Rheumatology (Oxford). 2017 Mar 1;56(3):378-383

31. Bansback N, Phibbs CS, Sun H, O'Dell JR, Brophy M, Keystone EC, et al. Triple Therapy Versus Biologic Therapy for Active Rheumatoid Arthritis: A Cost- Effectiveness Analysis. BAnn Intern Med. 2017 Jul 4;167(1):8-16.

32. Scott DL, Ibrahim F, Farewell V, O'Keeffe AG, Walker D, Kelly C, et al. Tumour necrosis factor inhibitors versus combination intensive therapy with conventional disease modifying anti-rheumatic drugs in established rheumatoid arthritis: TACIT non-inferiority randomised controlled trial. BMJ. 2015 Mar 13;350:h1046.

33. Choi HK, Seeger JD, Kuntz KM. A cost-effectiveness analysis of treatment options for patients with methotrexate-resistant rheumatoid arthritis. Arthritis Rheum. 2000 Oct;43(10):2316-27

34. Zhi-Chao Shi, Hong-Ping Fei, Zhi-Liang Wang. Cost-effectiveness Analysis of Etanercept Plus Methotrexate vs Triple Therapy in Treating Chinese Rheumatoid Arthritis Patients. Medicine (Baltimore). 2020 Jan;99(3):e16635

\section{Figures}




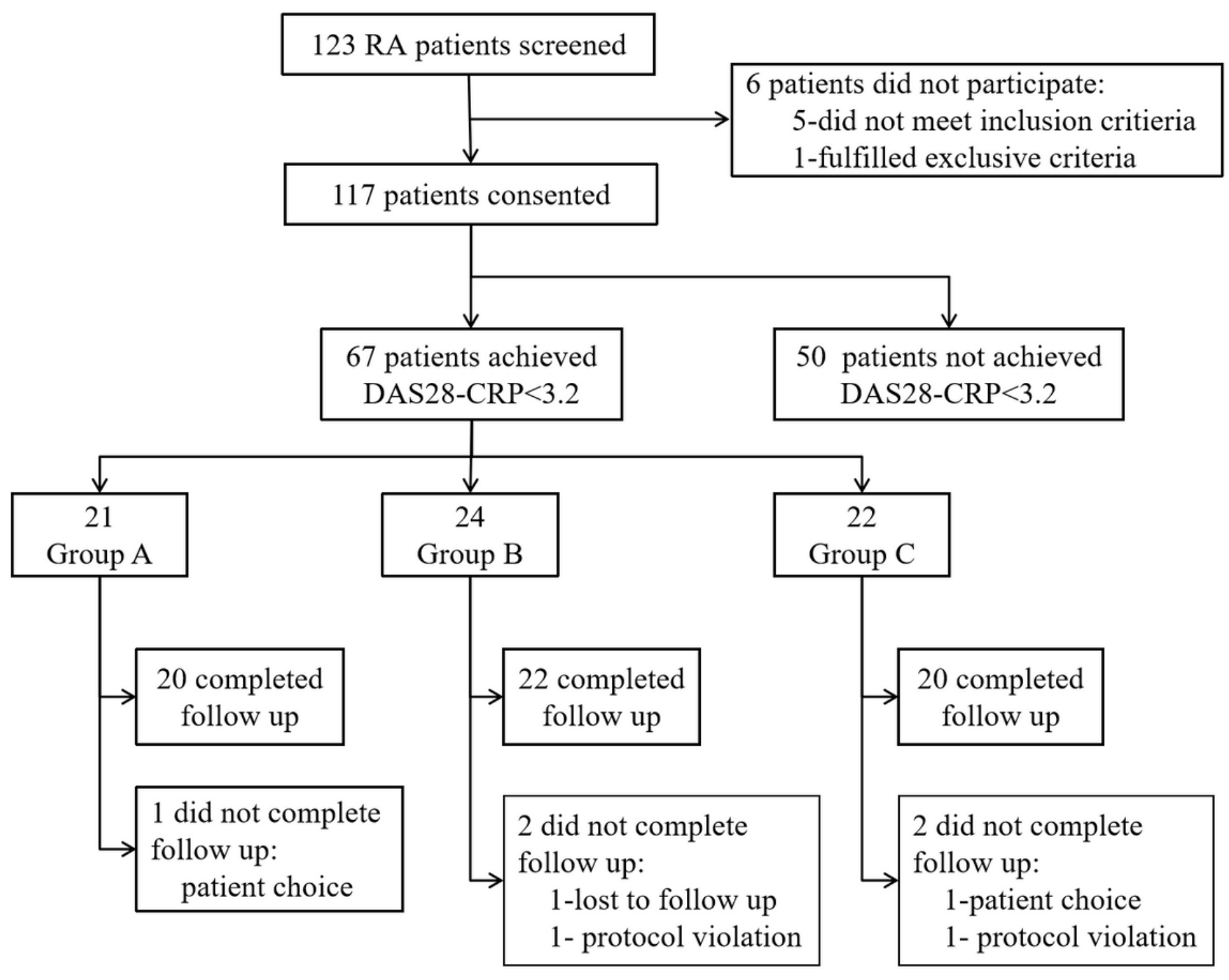

Figure 1

Consort diagram-patient progress through study. RA: rheumatoid arthritis; DAS: disease activity score; CRP: C-reactive protein. 


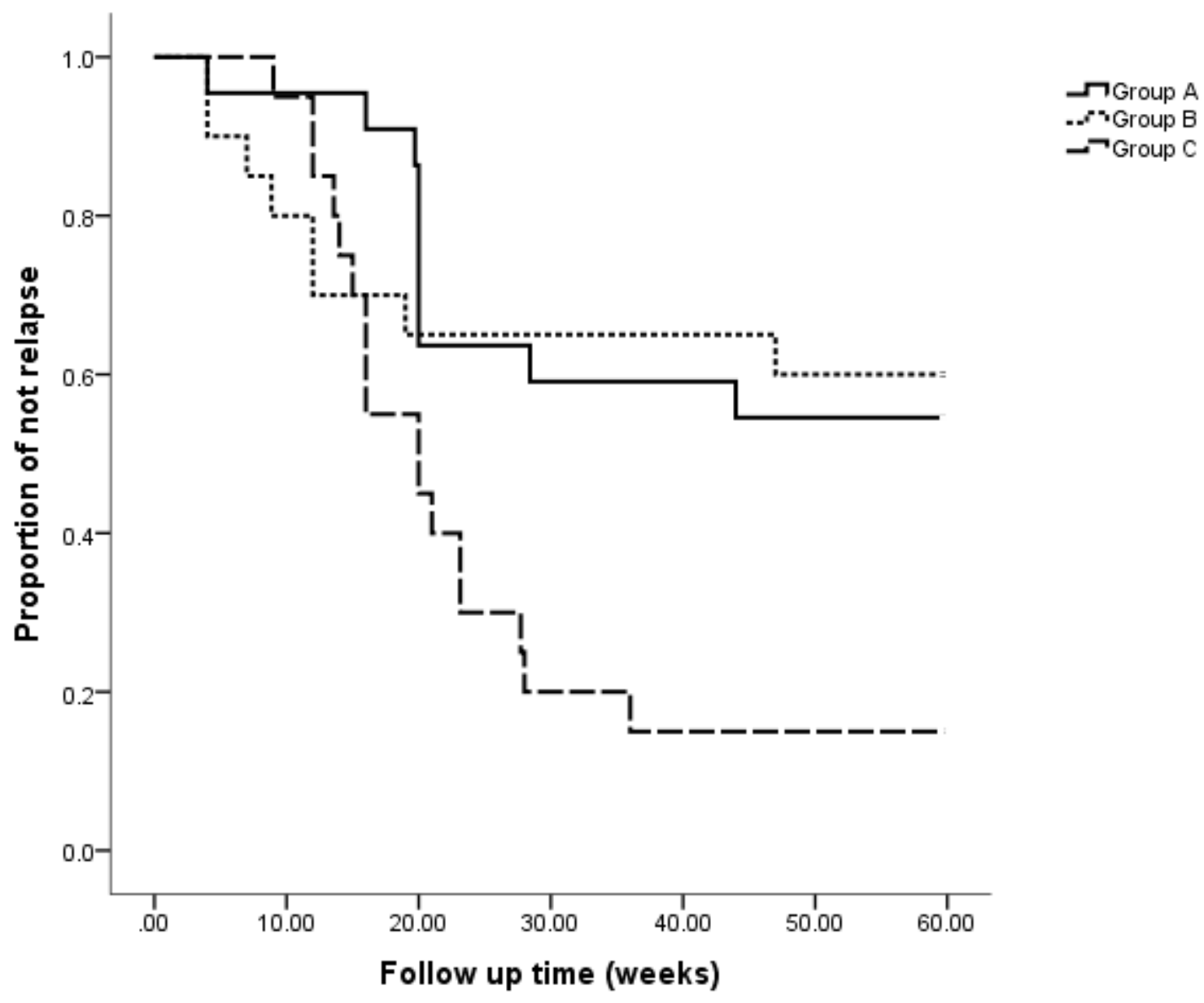

Figure 2

The Kaplan Meier Curve of disease relapse of the three groups

\section{Supplementary Files}

This is a list of supplementary files associated with this preprint. Click to download.

- supplementaryfigures.docx

- supplementarytables.docx 